\title{
Compliance, resistance and incipient compliance when responding to directives
}

\author{
Alexandra Kent \\ Loughborough University, UK
}

\begin{abstract}
How does a parent get a child to do something? And, indeed, how might the child avoid complying or seem to comply without actually having done so? This article uses conversation analysis to identify the interactionally preferred and dispreferred response to directives (compliance and resistance respectively). It then focuses on one alternative response option that has both verbal and embodied elements. The first part involves an embodied display of incipient compliance. That is, actions that are preparatory steps towards compliance and signal that it may be forthcoming, but which do not in themselves constitute compliance. Incipient compliance creates sequential space for a verbal turn that reformulates the ongoing action as autonomous, self-motivated behaviour on the recipient's part, rather than subject to the will of the directive speaker. This enables the recipient to maintain autonomy over their own conduct without provoking the conflict or repeat directives associated with outright resistance.
\end{abstract}

\section{Keywords}

Authority, children, compliance, conversation analysis, deontic rights, directives, family mealtimes, power, resistance 


\section{Introduction}

In our everyday lives we are frequently faced with situations where someone else attempts to get us to do something. Whether formulated as a proposal, suggestion, hint, request or outright command, all social control acts impinge on the recipient's freedom of action to some degree (Blum-Kulka, 1997; Pearson, 1989). This imposition has also been expressed as a threat to the recipient's face (Brown and Levinson, 1987; Goffman, 1967). Considerable research has been conducted into directives within various disciplines (e.g. Ervin-Tripp, 1976; Goodwin, 1990, 2006; Searle, 1979). This article builds on such work to consider how participants respond to 'utterances designed to get someone to do something' or, as they are often glossed, directives (Goodwin, 2006: 517).

Previous research has demonstrated two highly significant dimensions to directing: entitlement and contingency (Antaki and Kent, 2012; Craven and Potter, 2010; Curl and Drew, 2008; Heinemann, 2006). Entitlement refers to the extent to which the speaker displays a right to control the actions of the recipient and to expect compliance. Contingency refers to the degree to which the speaker acknowledges potential barriers to compliance in the design of the utterance (including willingness and ability).

Low entitlement and high contingency: Curl and Drew (2008: 138)

1 Doc Hello

$2 \quad \mathrm{Clr} \quad \mathrm{mt}$ ! Hello, I wonder if you could give me some advice

High entitlement and low contingency: Craven and Potter (2010: 432)

21 Mum Ri:gh'. Ea:' ya te:a now.

In the above example from Curl and Drew (2008) the utterance is formulated as a wondering about the recipient's ability to perform the desired action (giving advice). In the Craven and Potter (2010) example Mum does not wonder about her children's ability or willingness to eat their dinner. She straightforwardly tells them to eat their tea immediately. With this formulation Mum claims a total right to tell the recipient what to do, and does not orient to any potential factors that could prevent compliance.

Directive formulations vary in the degree to which the speaker assumes control over the recipient's actions, or the recipient retains autonomy over their own conduct. The diversity of directive formulations used in social interaction (from proposals to orders) can be taken as evidence of participants' attentiveness to issues of control and autonomy. The very fact that so many different ways of 'getting someone to do something' exist highlights the careful negotiation that can be required when initiating an action that impinges on another person's freedom of action. As Goodwin (1990: 208) states: rather than being simply a speech act designed to get something done, directives constitute a complex speech genre, one that is capable of encompassing a wide variety of speech forms and action (imperatives, assessments, descriptions, etc.) and turning them to its own purposes.

Directives have traditionally been conceptualized in the literature as an indicator of power and authority and a means through which such authority is asserted and ratified in social life (Ervin-Tripp, 1976; Jones, 1992; Pufahl-Bax, 1986; Sealey, 1999; West, 1990). However, traditional conceptualizations of authority as an essential character trait of a 'powerful person' (such as a parent) have failed to stand up to empirical examination (see Braine et al., 1991) and cannot account for the subtle, situated management of local entitlements observed in naturalistic data. Consequently, a more situated and fine-grained understanding of authority is required in order to explicate the action that takes place during directive sequences. The notion of entitlement provides a more nuanced understanding of the concerns being oriented to by participants during the exchanges that constitute a directive and its response (Curl and Drew, 2008; Heinemann, 2006).

Philosophical work on authority has postulated two main domains: epistemic and deontic. Epistemic authority relates to knowledge and concerns who has the right to know, assess or describe what. This aspect of authority has received serious and careful attention from conversation analysts (e.g. Drew, 1991; Heritage and Raymond, 2005, 2012; Heritage 2012a, 2012b; Perakyla, 1998, 2002; Raymond, 2000). Such work has shown how participants orient closely to the issue of who knows what and that they use delicate and precise interactional practices to manage 'their relative access to, or rights to assess, knowledge, events, behaviour, and the like in specific, locally organized sequences of talk' (Raymond and Heritage, 2006: 681). In contrast, deontic authority relates to decisions and obligations and is concerned with who can set the rules about what should be done, or "who prevails in decision 
making' (Allsopp, 1996; Bochenski, 1974; Lukes, 1979; Peters, 1967; Walton, 1997). This aspect of authority is just beginning to receive interest from within conversation analysis. However, recent findings suggest that, just like epistemic authority, 'deontic authority is an interactional accomplishment, claimed, displayed, and negotiated at the level of turn-by-turn unfolding of the interaction' (Stevanovic and Perakyla, 2012). These two domains of authority (epistemic and deontic) are distinct but related, and often co-occur in similar circumstances such as planning future actions: 'we both know our plans and decide about them' (Stevanovic, 2011: 3). Negotiations of both deontic and epistemic authority are highly relevant for participants when issuing and responding to directives.

Rather than focusing on the form of the directive itself, the current study examines the responses offered to several directives issued during family mealtime conversations. It will consider what resources are available to recipients for managing the conflicting assumptions of the speaker's entitlement and the recipient's autonomy.

\section{Data and method}

The data presented here are part of a corpus of video recordings of family mealtimes. Family mealtimes are an ideal site for the study of directives because they are 'densely packed', task-focused events (Feise et al., 2006: 77). Pearson (1989: 289) noted that "“controlling" speech acts or directives occur profusely in situations where people are set on accomplishing tasks'. For families with young children, the mealtime encounter represents a key site for the socialization of children into culturally and morally appropriate patterns of behaviour (Larson et al., 2006; Paugh, 2005). Family mealtimes are occasions when a lot of practical things need to happen in a short space of time (serving, eating, discussing future events) and attention is also paid to correcting manners and actions deemed socially unacceptable.

All participating families were given a camera and asked to film their meals as they felt happy and able to. They had the option of not recording or deleting any meal before submission to the researcher for any reason. The analysis centres on 13 hours of mealtime data recorded by three families, but drew on a further 26 hours of data recorded by a further four families and accessed from the data archives of the Discourse and Rhetoric Group (DARG) at Loughborough University.

The analytic approach used draws heavily on contemporary conversation analysis (Drew, 2008; Hutchby and Wooffitt, 2008; Schegloff, 1996). At the same time it will be guided by discursive psychological principles in considering the role of cognition or psychological states in unfolding action (Edwards, 1997; Edwards and Potter, 2005).

\section{Analysis}

Here I will briefly describe the preferred and dispreferred responses to a directive: compliance and resistance respectively. I will then consider a third response option, which I have termed 'incipient compliance' following an anecdotal noticing of the phenomenon by Schegloff (1989).

\section{Compliance}

A common and straightforward response found in the data is an entirely embodied response that performs the directed action without verbal comment (see Extract 1).

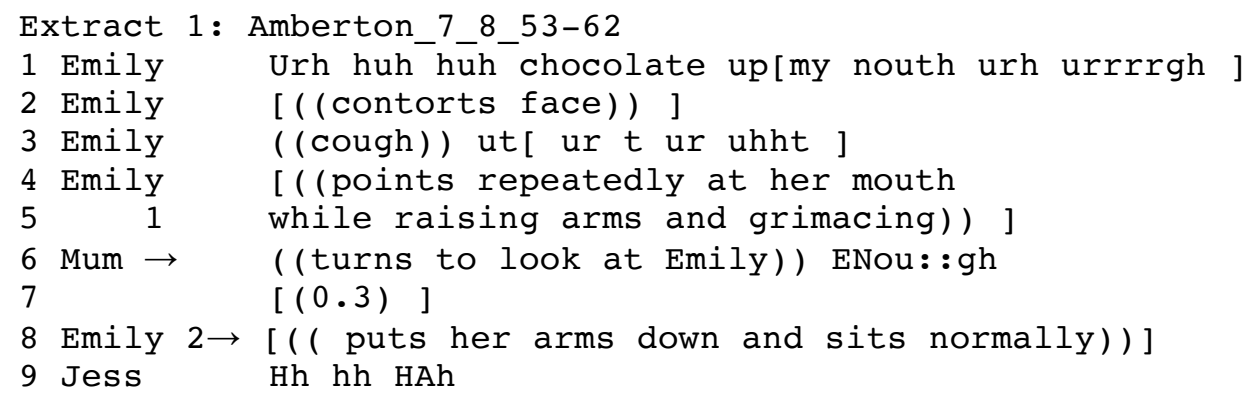


In Extract 1 Mum issues a rather vague directive 'ENou::gh' on line 6. Emily had been grimacing and waving her arms about (Figure 1). She immediately stops doing so and sits still and upright in her chair (Figure 2). She makes no verbal acknowledgement that Mum has directed her to stop her ongoing activity, but her embodied conduct displays both her receipt of, and compliance with, Mum's directive.

Her response is immediate, quick and unmitigated, carrying the markers associated with an interactionally preferred response (Schegloff, 2007). Craven and Potter (2010) demonstrated how directives can be designed to restrict the response options available to the recipient and very strongly project compliance as the appropriate and fitted next action. Evidence from within Development Psychology suggests that immediate compliance is the most common response to parental directives (Braine et al., 1991; Brumark, 2010; Kuczynski and Kochanska, 1990). Additionally, although not counted or coded specifically, immediate embodied compliance was a relatively common response option in my data and represents the smoothest and shortest type of directive sequence. These findings suggest that compliance is the preferred response to a directive (see Kent, 2012).

\section{Resistance}

If compliance is the preferred response, then resistance would be the dispreferred. In terms of sequence organization, Craven and Potter (2010) noted that resistance tended to stall progressivity and lead to upgraded (more entitled, less contingent), repeat directives (e.g. Extract 2).

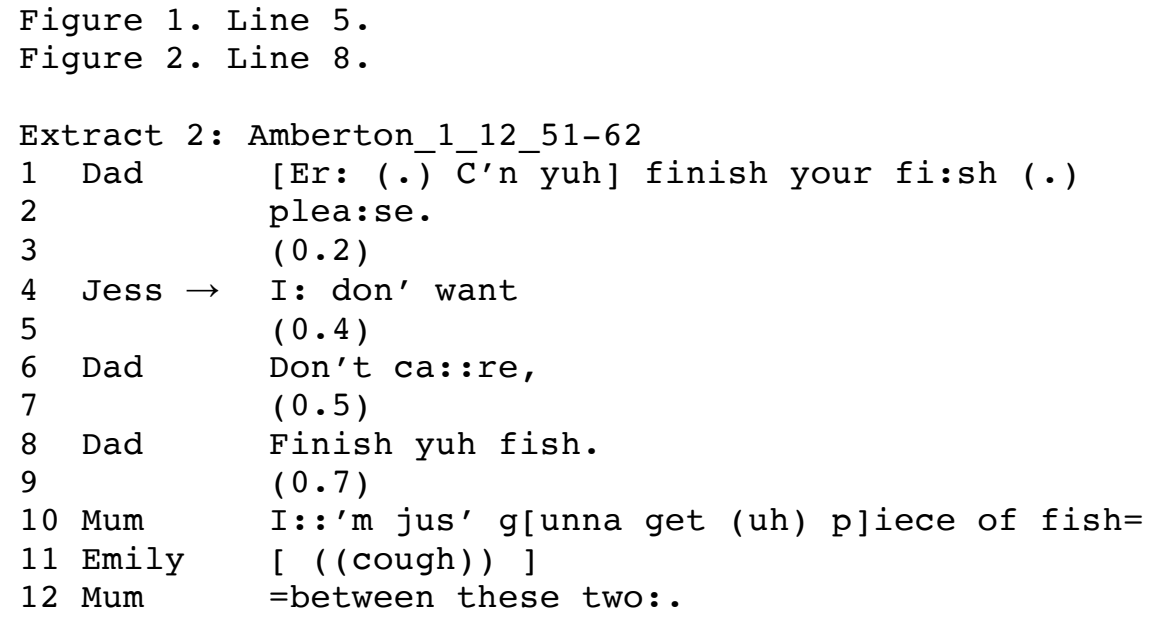

Following Dad's request on line 1 for Jessica to finish her fish there is a short delay before Jessica begins to formulate an account for not complying on the grounds that she doesn't want to. Her account is incomplete and does not explicitly articulate her refusal. In this sense it exhibits markers of dispreference (Schegloff, 2007). Dad then delivers a stronger directive 'Don't ca::re, (0.5) Finish yuh fish' on lines 6-8. Notably, he goes on record as having no concern for Jessica's free will or autonomy in this matter.

Extract 2 highlights the core dilemma for directive recipients: if they comply then they are (albeit temporarily) relinquishing their autonomy and submitting to the will of the speaker; if they resist then the control attempt typically gets stronger and harder to resist, progressivity is stalled and intersubjectivity is threatened. Neither option is always satisfactory. The rest of this article deals with a format for responding that can provide a middle ground between complying and resisting, which, crucially for the recipient, enables them to retain control over their actions.

\section{Multi-component responses}

Extract 1 showed that compliance can be entirely non-verbal. Therefore any verbal element in a compliant response is generally more than would be required to deliver a fitted response. It has the potential to moderate the action in some way. In Extract 3 below Mum directs Daisy not to talk with her mouth full. Daisy both visibly chews and swallows her food and verbally states that she has finished. 


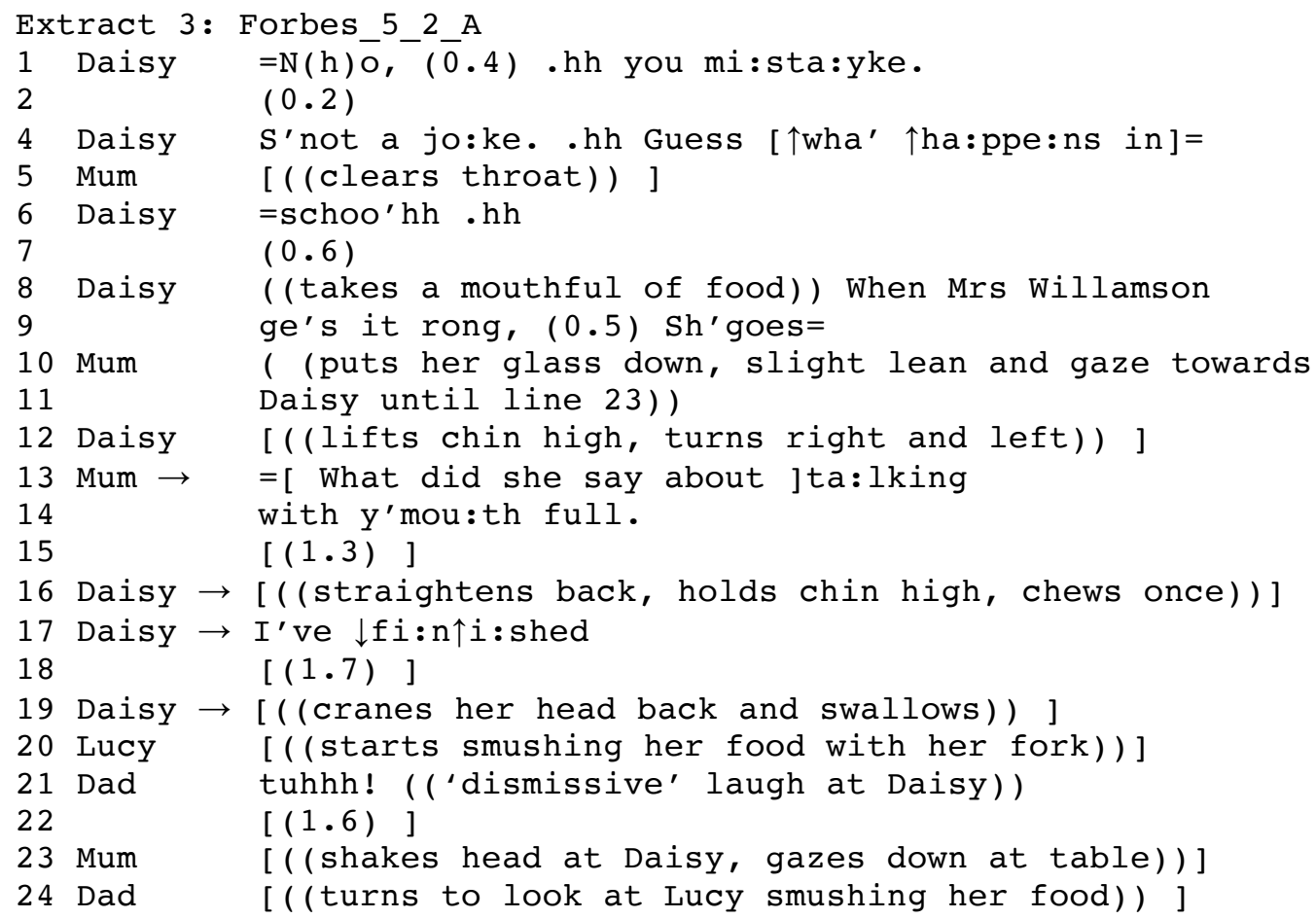

In Extract 3 Mum delivers an interrogative 'What did she say about ta:lking with y'mou:th full.' on lines 13-14. This utterance can be treated as a directive because it is issued at a point when Daisy is talking with her mouth full. Following the directive, Daisy then stops what she had been talking about and performs finishing her mouthful, thereby displaying her orientation to Mum's question as a directive (lines 15-19).1 Daisy's first response (line 16) not only orients to Mum's utterance as a directive, it also displays Daisy's stance towards that directive - namely compliance. However, Daisy does not just quietly and quickly comply with the directive and then continue speaking. Her compliance is energetically demonstrated with a crafted over-exaggeration. She holds herself ramrod straight and chews energetically (line 16).

Next, Daisy states 'I've $\downarrow$ fi:n $\uparrow$ i:shed' (line 17). At this point she hearably and visibly still has food in her mouth. As a verbal response to a directive not to talk with your mouthful, saying 'I've finished' through a mouthful of food is a defiant move. The fact that she has not finished is visibly and publicly available to all participants so her utterance is unlikely to have actually been designed to convince anyone of the emptiness of her mouth. Rather, it serves to defy the directive action by claiming to have complied when she very clearly has not. In so doing it rejects the rights asserted by the directive speaker. When a recipient resists a directive they refuse to cede control of their actions to the directive speaker.

In Extract 3 Daisy's verbal resistance turn offers an alternative (albeit visibly inaccurate) assessment of the state of her mouth. Mum's question directive has the first assessment of the state of Daisy's mouth embedded within it. When Daisy then offers a second, contradictory, assessment she disputes the grounds on which Mum's directive was issued and resists Mum's entitlement to tell her what to do. Typically, if the recipient resists or defies the directive, it tends to lead to the directive being reissued in an upgraded form (Craven and Potter, 2010). In this case no second directive is forthcoming. Following her defiant verbal turn, Daisy '((cranes her head back and swallows))' in the same over-egged style of performance with which she first responded to the directive (line 19). Her performance provides compliance with the directive (line 19). Mum and Dad then both refocus their attention away from Daisy, signalling that the sequence is at a close.

I suggest that the key to how this response avoids an upgraded or repeated directive lies in the precise order of the three stages to Daisy's response:

1. Perform chewing (line 16).

2. Verbally resist the directive (line 17).

3. Actually deliver compliance (line 19). 
Daisy's first action, and therefore sequentially the most contingently relevant as a responsive action, was to display a stance of compliance towards the directive and to perform an action on which full compliance would be contingent; namely chewing before swallowing. After this first stance has been displayed Daisy then challenges the grounds on which the directive was issued. Note that she does not challenge Mum's generic right to issue directives, just her basis for issuing this one. Finally, after Daisy has delivered her verbal resistance she then goes on to comply. The defiant, and potentially risky, stage in Daisy's response is sandwiched between the two displays of compliance, thereby moderating its tone and significance.

Note also that the displays of compliance are not just 'doing compliance'; they are 'doing a performance of compliance'. The embodied displays of compliance can only mitigate the defiant nature of Daisy's verbal turn if her interlocutors treat it as sequentially relevant. By making her show of compliance so exuberant and unmistakeably compliant, Daisy works to maximize the chance it will be noticed and therefore mitigate her defiant verbal turn. She makes it clear that she is complying, despite challenging Mum's entitlement to have issued the directive.

The embodied and verbal response is not just the multimodal delivery of one response. It is a series of different and contrastive responses utilizing different modalities. The sequential ordering of the embodied and verbal responses enables the recipient to resist the directive action and challenge the speaker's right to control their actions without provoking an upgraded repeat directive.

\section{Why complicate compliance with resistance?}

In Extract 4 Mum directs Jessica to 'phlea:se $<$ finish your $\uparrow$ soup $>$ '. Jessica responds with a mixture of embodied and verbal turns. Prior to the extract Jessica has been taking a long drink from her glass. This extract begins with Jessica finishing her drink in one long downing motion.

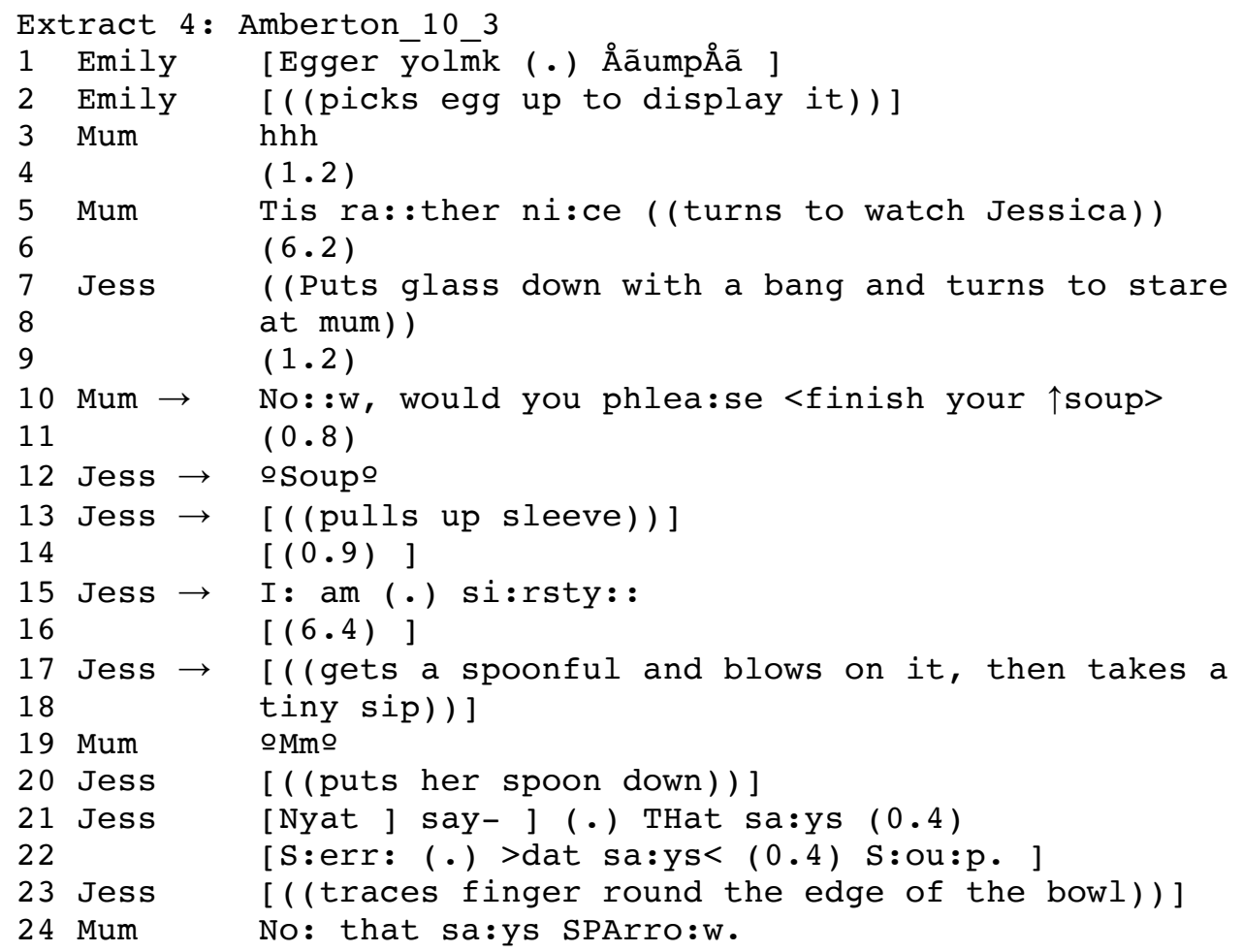

Mum issues a directive on line 10. Despite Mum's turn being prefaced with a 'now', Jessica delays 0.8 seconds before quietly repeating the object of the directive 'Soup (line 12). It is a minimal receipt of the directive, which embodies no orientation to either compliance or resistance. What it does do is buy time and space, incrementally delaying compliance a little more at each step. Jessica then pulls up her sleeve (line 13). 'finish your $\uparrow$ soup' is a bigger task than simply eating soup. Jessica has more than one 
spoonful of soup left in her bowl so compliance is not something that could reasonably be completed in the space of one turn. In such a context, Jessica's embodied response displays an orientation to compliance by performing a preparatory action upon which a large task, such as finishing her soup, may be contingent. In addition to displaying a stance of compliance, the act of pulling up her sleeve takes time, delaying full compliance still further from the directive.

Following her embodied display of pulling her sleeve up, Jessica then says 'I: am (.) si:rsty::' (line 15). This utterance performs a number of actions. First, it challenges the basis for issuing the directive. It offers an account for why Jessica was not eating prior to the directive. It formulates her earlier drinking as a normal, reasonable part of mealtime behaviour, rather than deviant behaviour subject to sanction. This casts 'not-eating' as justified when one is thirsty. In so doing Jessica resists the implicit criticism of 'not eating' carried by the directive. By treating drinking as normal mealtime behaviour, Jessica treats Mum's directive as unnecessary (as though she would have got round to eating eventually on her own accord). This challenges the deontic grounds on which Mum issued the directive.

Jessica's verbal turn also accounts for the delay in compliance thus far. This continues the work of the earlier responses in delaying the production of actual compliance. Note also that Jessica says 'I am thirsty' not 'I was thirsty'. The use of the present tense brings Jessica's earlier, self-motivated drinking back into relevance in the new sequential environment where a directive response is required.

Following her verbal resistance, Jessica then spends 6.4 seconds with more 'getting ready to comply' as she blows on the soup, and eventually offers a demonstration of actual compliance when she sips a small spoonful of soup (lines 17-18). Once again, the recipient 1) performs action that can be taken as a preliminary to compliance, but does not in itself constitute compliance, 2) verbally challenges the speaker's entitlement to have issued the directive, and then 3) goes on to comply. Note that Jessica takes about the smallest mouthful of soup possible. She then stops eating and puts her spoon down (line 20). This is about the most minimal display of compliance with a directive to 'finish your $\uparrow$ soup' as one can think of. Jessica then launches a new topic of conversation about the writing on her bowl, which Mum engages in without further reference to finishing the soup at this stage (lines 21-24).

What would constitute full compliance with a directive such as 'finish your soup?' It seems unlikely that the family would sit in silence, deferring all other conversations, until Jessica has finished her bowl. What might constitute an acceptable demonstration of compliance with a directive like 'finish your soup' is rather ambiguous and open to negotiation between the participants. This ambiguity is something that can be exploited by recipients during their response, such as Jessica taking only a tiny sip of soup.

The directive is also ambiguous in terms of action. 'No::w, would you phlea:se $<$ finish your $\uparrow$ soup $>$ ' carries an embedded accusation or admonishment that Jessica's prior conduct was inappropriate or unacceptable.2 The hidden message is 'you weren't finishing your soup beforehand and you should have been'. Jessica must attempt to respond to the directive in a manner that won't prompt her mother to reissue or upgrade it, whilst simultaneously dealing with the accusation of inappropriate behaviour. This necessitates maintaining a balance between compliance and resistance, and taking care to manage the live issues of autonomy and morality.

The combination of the first (embodied) and second (verbal) responses means that when full-embodied compliance occurs in Extract 3 and Extract 4 it is in a different sequential environment than the compliance offered in Extract 1. The first stance Jessica offers towards the directive to ' $<$ finish your $\uparrow$ soup >' projects compliance (she pulls her sleeves up), but it does not itself constitute compliance. Her verbal utterance then challenges the grounds of the directive, resists its projection of compliance and announces a current state of being. When full-embodied compliance is finally delivered it is after Jessica's verbal turn, not her mother's directive. Consider the following actions (they are a gloss of Jessica's part of the interaction):

1. Jessica finishes her drink and puts the empty glass back on the table.

2. She announces she is thirsty, despite having just finished a drink.

3. She then takes a drink of the soup in front of her.

This sequence makes sense even without the directive having being issued. Through her verbal turn Jessica reformulates the ongoing action as being under her control rather than merely complying with her mother's directive. After announcing she is thirsty, going on to drink a spoonful of soup appears to 
be self-motivated behaviour rather than responsive to the directive.

The careful balance between complying, resisting and acting autonomously is made possible by the nature of the first embodied response. It holds off an upgraded repeat directive by showing a compliant orientation. In so doing it creates the sequential space for the verbal turn. The verbal turn resists the directive and casts any subsequent embodied action as not solely due to the directive, but also responsive to the ongoing action the recipient was engaged in.

\section{Incipient compliance}

These extracts are examples of a phenomenon Schegloff termed 'incipient compliance' when he noticed it somewhat anecdotally during his analysis of a directive sequence (1989: 146). He suggests that the preferred response following a directive is either a compliant action or some behavioural indication that such an action or course of action is being launched. He describes actions that indicate future compliance (such as transferring a fork from one's right to left hand following a directive to use a knife) as incipient compliance. That is, an action that moves towards compliance without actually getting there (although the right hand is now free to pick up a knife, the knife itself has not yet been used). Schegloff (1989) distinguishes incipient compliance from full compliance on the grounds that the recipient 'does not actually go on to comply at this point' despite performing preparatory actions (1989: 146). Incipient compliance takes the form of actions that can be completed as a precursor to compliance or as part of getting ready to comply.

Extract 5 helps to illustrate the concept of incipient compliance more clearly. It is different from Extracts 3 and 4 in that Emily offers no verbal resistance to Dad's directive that she 'Ea:t ni:cely 'please- ${ }^{\circ}$ ' on line 4 . However, approximately 30 seconds elapse before she takes a mouthful. The question to consider is whether Emily complies with the directive straight away or not. Prior to this extract Mum and Dad have been talking while Emily eats her dinner. Emily has recently taken a large forkful into her mouth and is having difficulty chewing. When the extract starts she is looking at Dad, struggling to chew.

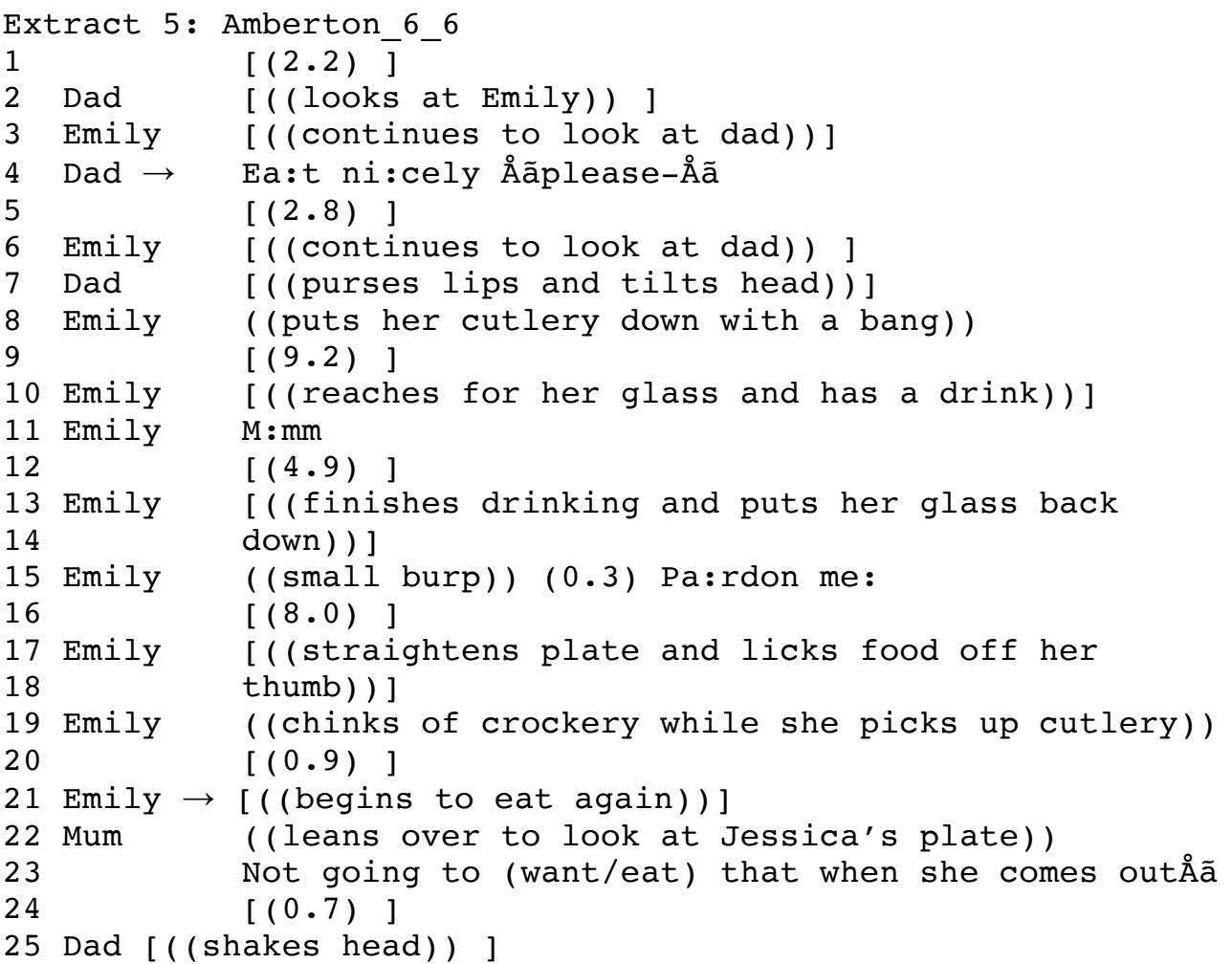

Dad's directive on line 4 is followed by a 2.8-second pause during which time Emily freezes, stopping her ongoing action (line 6), and Dad purses his lips as a display of something perhaps akin to disappointment or disapproval (line 7). Emily's initial embodied response receipts the directive by 
halting the prior behaviour, suggesting a stance of compliance, but stops short of actually displaying that compliance. Between lines 8 and 20 Emily then engages in an extensive series of actions, none of which constitute eating (nicely or otherwise), but all of which could be taken as a precondition to eating nicely. At the time of the directive being issued Emily has a full mouth. She then puts her cutlery down on line 8; it would be impolite to place more food in an already full mouth. She takes a drink to clear her mouth (lines 9-10). Her gustatory 'M:mm' on line 11 signals that the problem of an overfull mouth is now being resolved and she is one step closer to compliance. Her ' $\downarrow$ Pa:rdon me:' on line 15 shows an orientation to politeness, which is inherent in 'eating nicely'. She straightens her place and cleans the mess of her large mouthful from her fingers on lines 17-18. This tidies up her eating area and now sets her up to eat nicely without being inhibited by her previous mess. She picks up her cutlery on line 19 and finally begins to eat on line 21; around 30 seconds after she was first directed to eat.

Throughout all of Emily's embodied actions Mum and Dad sit silently watching her.

As soon as Emily has actually eaten a mouthful of food Mum displays a change in her attention by leaning over to look at her other daughter's plate - Jessica is currently away from the table. Mum then comments to Dad: 'Not going to (want/eat) that when she comes out' (lines 22-23). Dad agrees with Mum by shaking his head on line 25 . This clear-cut refocusing, without acknowledging the recipient's compliance, is a recurrent means of signalling the end of a directive sequence. This exchange provides us with evidence that Emma's parents treat the directive sequence as complete only once she has eaten. All the embodied actions that took place in the intervening 30 seconds were not treated as sufficient compliance for the sequence to be signalled as complete by a new topic launch. In other words, full compliance here means 'eat'.

Extract 5 offers further insight into the issue of what constitutes compliance. Arguably, directives containing adverbs such as 'Ea:t ni:cely ${ }^{\circ}$ please- ${ }^{\circ}$ ' can be ambiguous with regards to what constitutes compliance - is the sought after response, a) a display of appropriate moral behaviour or b) food in the mouth? Emily's actions between lines 8 and 20 are displays of 'nice' behaviour, but it is only when she definitively eats on line 21 that her parents treat her as having complied with the directive. To 'eat' is a demonstrable, visible act that has a fixed point both in time and in the conversation. 'Nice' is a more qualitative descriptor of action over time. In Extract 5, the participants appear to treat the event of 'eating' as constituting compliance, rather than the less fixed adjective 'nicely'. This could be because the fixed event status of 'eat' can more easily be treated as part of the turn taking structure, relevant and consequential for the interaction than 'nicely'. When dealing with embodied actions as responsive turns in conversation, their ability to slot into a turn-at-talk could be an important factor in whether they are treated as interactionally meaningful. Compliance in these cases might therefore be negotiable to a certain extent in terms of defining what the participants will treat as evidence of full compliance.

The ambiguity of 'Ea:t ni:cely ${ }^{o}$ please-' (line 4) is not limited to the difficulty in ascertaining what would constitute full or sufficient compliance. The directive also contains within it an admonishment or accusation that Emily was not eating nicely prior to the directive being issued. This embedded action means that any response must manage both the directive's move to control the recipient's actions and the admonishment's threat to the recipient's social face by accusing her of transgressing or violating the moral order. It could be that the technique of incipient compliance and verbal resistance is particularly suited to managing issues of both epistemic agency and multiple embedded actions in ambiguous directives.

Emily's actions between lines 8 and 20 are an extended example of incipient compliance; they are actions that move towards compliance without actually getting there. Incipient compliance treats the prior utterance as a directive action. It receipts the speaker's turn and its intended recipient, acknowledges the action embedded within that turn and projects a preferred response (compliance). In so doing it attends to potential problems with speech, hearing or understanding that could prompt a repair initiator or a repeat directive. It also manages threats to intersubjectivity and progressivity. Crucially, however, it does not perform full compliance. By withholding full compliance at this stage the recipient does not accept the directive speaker's right to control their actions.

\section{Interactive impact of incipient compliance}

Preventing a repeated or upgraded directive appears to be a vital feature of incipient compliance. 
Repeat directives display more entitlement, orient less to contingencies and further restrict the response options for recipients (Craven and Potter, 2010). With each successive upgrade, repeat directives progressively reduce the recipient's ability to act autonomously. This makes incipient compliance a crucial instrument in their response toolkit.

Incipient compliance works to forestall or prevent upgraded directives by projecting full compliance as being 'in the offing'. It displays a stance towards the directive and projects a preferred response. By projecting an upcoming preferred response, the recipient buys him/herself time and space in the conversation without immediate sanction. I do not think it is too much of an interpretive stretch to suggest that had Emily performed actions that did not project full compliance, Mum and Dad would not have sat silently, watching her for 30 seconds without reissuing the directive.

In addition to avoiding an escalation of the directive sequence, the time 'bought' for the recipient through incipient compliance serves to shift full compliance away from direct sequential adjacency to the directive. This makes it less clear whether the embodied compliance is a responsive action or just individual physical movement unrelated to the conversation. It buys the recipient time to respond; the more time they can delay, the less sequentially relevant full compliance becomes and the more likely the sequence is to be dropped in favour of other topics of conversation.

The interactional implications of blurring the responsive nature of an embodied response can be seen more clearly in Extract 6 below. This extract begins with Lucy eating cereal with her fingers. Dad initiates a directive action in two parts: 1) 'Da:on' [pick at i'] plea::se' and 2) 'Y'need to eat it ni:cely'". Although it takes place over two turn construction units (TCUs), Dad's utterance appears to be delivered as a single directive rather than an original and a repeat or upgrade. After a 0.4 -second gap (line 14), Lucy responds by saying ' $\uparrow \mathrm{I} a \mathrm{~h}(\mathrm{~h})[\mathrm{a}:(\mathrm{h}) \mathrm{m}$ ' and, in overlap, letting her food fall from her fingers back into the bowl (lines 15-17).

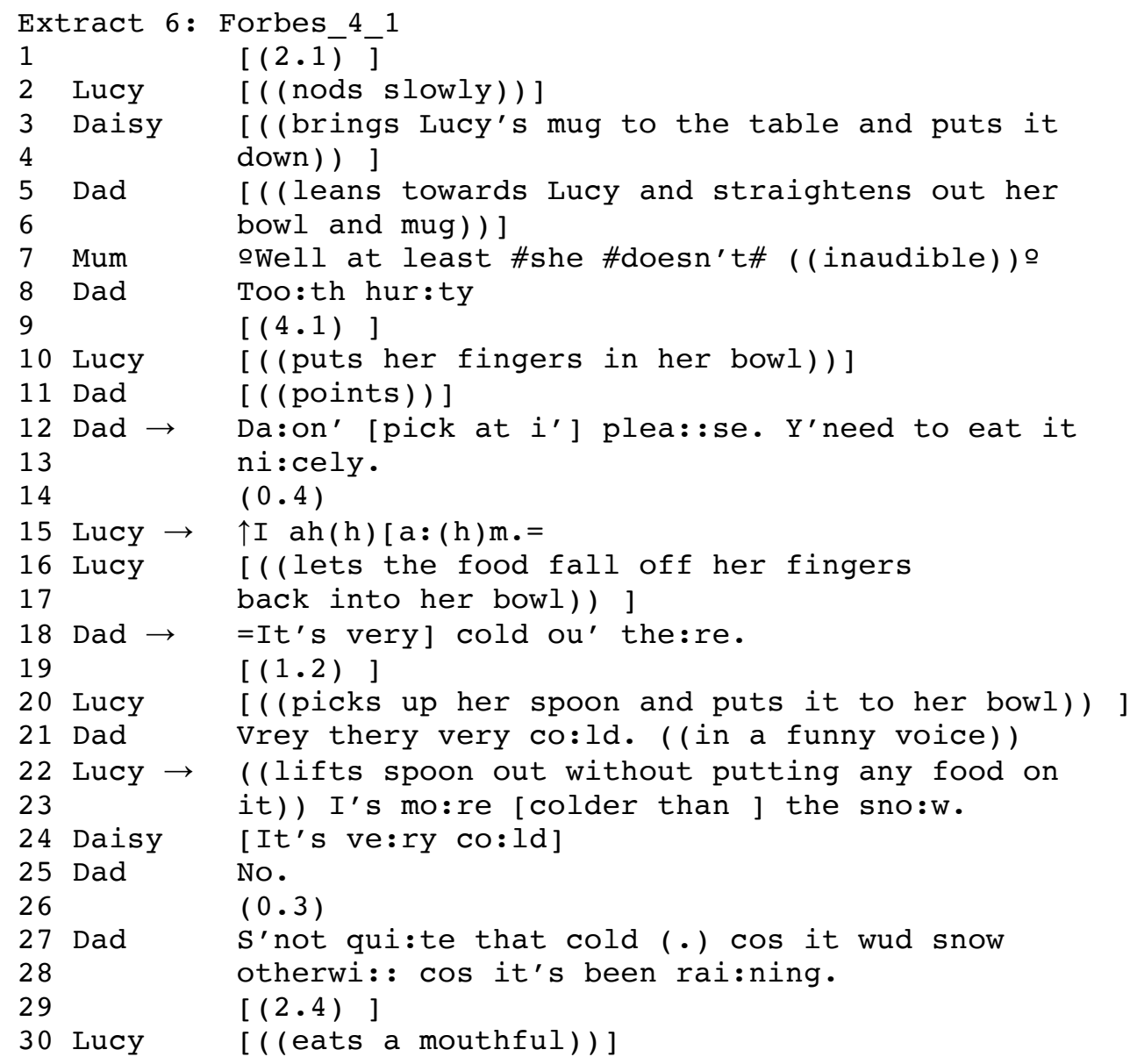

Unlike the other extracts in this collection, Lucy's initial response to the directive is a verbal resistance turn; she exclaims ' $\uparrow \mathrm{I}$ ah(h)[a:(h)m.' (line 15). This refutes the assessment embedded within Dad's 
directive that she is not currently eating nicely. In so doing she challenges the grounds on which the directive was issued in much the same manner as the verbal resistance turns in other extracts. Lucy asserts, from second position, her primary epistemic rights to know/assess her own state of being.

Extract 6 is unusual in that the verbal resistance turn is uttered as a first response rather than being held back until after a display of embodied incipient compliance. Unlike the other verbal resistance turns, ' $\uparrow \mathrm{I}$ ah(h)[a:(h)m.' has particles of aspiration interpolated within it. Potter and Hepburn (2010: 1552) suggest that Interpolated Particles of Aspiration (IPAs) can be used to 'modulate potentially problematic actions'. The inclusion of IPAs in Lucy's talk at this point may 'display trouble with the action at the same time as doing it' and so convey Lucy's awareness that openly refuting her father's grounds for telling her what to do is a risky activity, whilst still daring to do so (Potter and Hepburn, 2010: 1552). This offers further evidence of the dispreferred nature of resisting a directive. It also supports the argument that embodied incipient compliance may buffer the risky nature of verbal resistance. In the absence of embodied incipient compliance, Lucy inserts alternative verbal markers of the trouble with her turn - markers that were not required in other extracts where embodied incipient compliance preceded the verbal resistance.

Note that embodied incipient compliance is not absent from this turn, just delayed a little. The second half of Lucy's verbal turn overlaps with her embodied action of dropping bits of cereal from her fingers back into the bowl (lines 16-17). Although Lucy's initial response did display a resisting stance to the directive, it was accompanied by the embodied projection of upcoming compliance in short order.

Just as in other extracts, there is some ambiguity in the directive in Extract 6. First, the directive is issued in two parts: 1) 'Da:on' [pick at i'] plea::se' and 2) 'Y'need to eat it ni:cely'. This makes two separate complying actions relevant: 1) stop picking at the food, and 2) eat the food. It is not clear from the directive which complying action would be treated as full compliance. Lucy's action on lines 16-17 (dropping the cereal from her fingers back to the bowl) does offer full compliance to the first injunction, but only incipient compliance to the second directive. However, Lucy herself signals which directive she is orienting to, and therefore what she is treating as displaying full compliance when she says ' $\uparrow \mathrm{I}$ ah(h)[a:(h)m.' (line 15). This only makes sense as a response to the second half of Dad's turn, suggesting Lucy is treating his second directive as the one to which she will respond. By responding to the second directive rather than the first, Lucy is also conforming to the preference for contiguity noted by Sacks whereby if two questions are asked in a single turn, the respondent deals with the second question first (Sacks, 1987). On these terms her embodied conduct on lines 16-17 can be classified as incipient compliance; removing food from one's fingers and returning it to the bowl can be taken as a precursor to eating nicely.

The change in order of the different elements of her response, although non-typical and potentially more risky, enables Lucy to define exactly what she is responding to before she displays her stance to the directive. Here we can begin to see how Lucy asserts her own control over her actions from the very start of her response while simultaneously managing the risks of repeated and upgraded directives associated with unmitigated verbal resistance.

At the end of line 17 a directive has been issued, and it has received verbal resistance and embodied incipient compliance in response. Typically, we might anticipate the conversation to be essentially put on hold while the recipient moves from incipient to full compliance, as happened in earlier extracts. In Extract 6 the waiting does not happen. Dad launches a new topic immediately following Lucy's verbal resistance. Just as Lucy finishes saying ‘ $\uparrow \mathrm{I}$ ah(h)a:(h)m’ Dad initiates a new topic about the temperature (line 18); in fact his talk is latched on to the end of Lucy's utterance. It is not clear to whom he is addressing his talk, as initially there is no uptake (line 19). Lucy continues to demonstrate embodied incipient compliance (line 20) and Dad pursues a response to his new topic, this time with humorous intonation (line 21). It may be that Dad was attempting to initiate talk with Daisy while Lucy complied with his directive. At the time he was the only parent at the table, so that may have contributed to the unusual pattern. However, such an assertion is merely speculation at this stage. By line 21 Dad's initial topicalization of the temperature on line 18 has been confirmed as an initiating action in a new sequence of talk that requires a response rather than an aside or throw away comment not intended for interactional pick-up.

Once Dad has shown he is pursuing the new topic Lucy immediately undoes her recent incipient compliance by removing her spoon from the bowl without loading food onto it (lines 22-23). She does 
not progress from incipient compliance to full compliance. Lucy then offers a second assessment to Dad's first assessment on lines 18 and 21. Lucy is able, admittedly through Dad's uncharacteristically early topic launch, to make actual compliance redundant once her incipient compliance had continued past a topic boundary in the verbal conversation.

Lucy does in fact go on to eat a mouthful at line 30 but it would be hard to show this as a responsive action to the directive on lines $12-13$ in terms of sequence organization. At this point her eating has more the character of the individual physical actions that take place during mealtimes outside of the turn taking structure of the verbal conversation. Delaying the response beyond the topic shift means it is no longer a responsive action to the directive.

\section{Discussion}

The interactionally preferred response to a directive is immediate, embodied compliance. Verbal resistance with no sign of upcoming compliance is a dispreferred response and typically leads to an upgraded repeat directive. The data presented here reveal an alternative, multi-component response to directives. This response combines an embodied display of incipient compliance with a verbal turn that resists the directive or reformulates the ongoing action as self-motivated. This carefully timed combined response can enable the recipient to maintain autonomy over their own conduct without openly resisting the directive and provoking an even more forceful social control act. The key features of incipient compliance are that it:

- $\quad$ receipts the prior utterance nonverbally, treats it as a directive and displays an orientation to comply with the directive;

- $\quad$ projects compliance as being 'in the offing', thereby forestalling a repeated or upgraded directive; and

- $\quad$ shifts full compliance away from direct sequential adjacency to the directive, making it less clear whether it is a responsive action.

Incipient compliance provides a space for verbal resistance turns that challenge the grounds on which the directive actions are issued (thereby defying the speaker's entitlement to have issued the directive). They also appear designed to reformulate the ongoing action as self-motivated, rather than subject to the will of the directive speaker. This is a crucial aspect of the response work done by the recipients. The embodied incipient compliance and the verbal reformulations/resistance turns create a new sequential environment for compliance to the one that existed immediately after the directive actions had been initiated. If the recipient were now to go on to perform embodied actions consistent with those prescribed by the directive, they would do so under their own control rather than as an actor of the directive speaker's will.

The current study contributes to the development of an empirically grounded conceptualization of authority in interaction and builds on earlier work concerned with how speakers claim the right to make decisions about their own or other people's future actions (Cekaite, 2010; Curl and Drew, 2008; Goodwin, 1980; Heinemann, 2006; Jones, 1992; Pufahl-Bax 1986; Stevanovic, 2011; Vine, 2009; West, 1990; Wootton, 1997). It highlights the need to take situated meanings and sequential understandings into account and to avoid assuming that social roles or perceived status hierarchies grant an automatic entitlement to direct. Further work is needed to fully unpick the distribution and negotiation of deontic rights in interaction in a similarly fine-grained manner to the existing work on epistemic rights.

It is of course relevant to note that all the examples presented here involve parents addressing directives to their children. It remains to be seen to what extent the issues of autonomy and authority that are demonstrably live in parent-child interaction are repeated in other settings, with possibly fewer assumptions of asymmetry between the participants.

Incipient compliance and verbal reformulations form part of a toolkit of response options. They are particularly useful to participants who find themselves in second position to initiating actions that generate an asymmetry between participants by claiming unequal rights (either epistemic or deontic). In this respect incipient compliance and verbal reformulations appear to perform an equivalent action when responding to directives that repetitional responses perform when responding to polar questions (Heritage and Raymond, 2012). That is, they go along with the course of action projected by the first 
pair part, but seize primary rights to assess, describe and control that course of action. When responding to a directive it means that the action performed is not actually compliance, but is an arguably identical physical movement that forms part of the recipient's normal, self-motivated individual mealtime behaviour.

In the situation where a parent told their child to stop waving their knife around, the difference between compliance and self-motivated behaviour is arguably negligible. The result in both cases is that a sharp implement is no longer in danger of hitting them or their child in the head. For the child who seeks to attain full membership status in interaction with the same participation rights as their adult interlocutors, the difference is vast. If they comply they are no more than a mere vehicle for their parent's will, whereas selfdirected action gives them responsibility for, and control over, their conduct. Heritage and Raymond (2005) state that regulating and sanctioning our epistemic rights in relation to our interlocutors is part of Goffman's (1983) 'interactional housekeeping' that is a 'condition of personhood and even sanity' (Heritage and Raymond, 2005: 36). To that I would add the management of our deontic rights.

Funding

This research is based on work supported through an ESRC 1+3 PhD studentship.

Notes

1. Mum's utterance on lines 13-14 is plainly different from, for example, 'Don't speak with your mouthful'. It is done more indirectly, but the delivery does similar things; namely it highlights a problematic behaviour and leaves the recipient with the clear understanding that some form of corrective conduct is required.

2. I'm particularly grateful to Jeff Robinson for spotting the accusatory/admonishing element in the directives and encouraging my analysis of them at ICCA10.

References

Allsopp ME (1996) Deontic and epistemic authority in Roman Catholic ethics: The case of Richard McCormick. Christian Bioethics 2(1): 97-113.

Antaki C and Kent A (2012) Telling people what to do (and, sometimes, why): Contingency, entitlement and explanation in staff requests to adults with intellectual impairments. Journal of Pragmatics 44: 876-889.

Blum-Kulka S (1997) Dinner Talk: Cultural Patterns of Sociability and Socialization in Family Discourse. Mahwah, NJ: Lawrence Erlbaum.

Bochenski JM (1974) An analysis of authority. In: Adelman FJ (ed.) Authority. The Hague, The Netherlands: Martinus Nijhoff, pp. 56-85.

Braine LG, Pomerantz E and Lorber D (1991) Conflicts with authority: Children's feelings, actions, and justifications. Developmental Psychology 27(5): 829-840.

Brown P and Levinson SC (1987) Politeness: Some Universals of Language Usage. Cambridge: Cambridge University Press.

Brumark A (2010) Behaviour regulation at the family dinner table. The use of and response to direct and indirect behaviour regulation in ten Swedish families. Journal of Child Language 37: 1065-1088.

Cekaite A (2010) Shepherding the child: Embodied directive sequences in parent-child interactions. Text and Talk 30(1): $1-25$.

Craven A and Potter J (2010) Directives: Entitlement and contingency in action. Discourse Studies 12(4): 419442 .

Curl T and Drew P (2008) Contingency and action: A comparison of two forms of requesting. Research on Language and Social Interaction 41(2): 129-153.

Drew P (1991) Asymmetries of knowledge in conversational interactions. In: Markova I and Foppa K (eds) Asymmetries in Dialogue. Hemel Hempstead: Harvester Wheatsheaf, pp. 21-48.

Drew P (2008) Conversation analysis. In: Smith JA (ed.) Qualitative Psychology: A Practical Guide to Research Methods. London: SAGE, pp. 133-159.

Edwards D (1997) Discourse and Cognition. London: SAGE.

Edwards D and Potter J (2005) Discursive psychology, mental states, and descriptions. In: Te Molder H and Potter J (eds) Conversation and Cognition. Cambridge: Cambridge University Press, pp. 241-259.

Ervin-Tripp S (1976) Is Sybil there? The structure of some American English directives. Language in Society 5: 25-66.

Feise BH, Foley KP and Spagnola M (2006) Routine and ritual elements in family mealtimes: Contexts for child well-being and family identity. New Directions for Child and Adolescent Development 111: 67-89.

Goffman E (1967) Interaction Ritual: Essays on Face to Face Behavior. New York: Doubleday.

Goffman E (1983) Felicity's condition. American Journal of Sociology 89: 1-53.

Goodwin MH (1980) Directive-response speech sequence in girls' and boys' task activities. In: McConnell-Ginet S, Borker R and Furman N (eds) Women and Language in Literature and Society. London: Praeger, pp. 157-173.

Goodwin MH (1990) He-Said-She-Said: Talk as Social Organization among Black Children. Indianapolis: Indiana 
University Press.

Goodwin MH (2006) Participation, affect, and trajectory in family directive/response sequences. Text and Talk 26(4-5): pp. 515-543.

Heinemann T (2006) 'Will you or can't you?': Displaying entitlement in interrogative requests. Journal of Pragmatics 38: 1081-1104.

Heritage J (2012a) Epistemics in action: Action formation and territories of knowledge. Research on Language and Social Interaction 45(1): 1-29.

Heritage J (2012b) The epistemic engine: Sequence organization and territories of knowledge. Research on Language and Social Interaction 45(1): 30-52.

Heritage J and Raymond G (2005) The terms of agreement: Indexing epistemic authority and subordination in talk-in-interaction. Social Psychology Quarterly 68(1): 15-38.

Heritage J and Raymond G (2012) Navigating epistemic landscapes: Acquiescence, agency, and resistance in responses to polar questions. In: Ruiter JP (ed.) Questions: Formal, Functional and International Perspectives. Cambridge: Cambridge University Press, pp. 179-192.

Hutchby I and Woofitt R (1998) Conversation Analysis. Cambridge: Polity Press.

Jones K (1992) A question of context: Directive use at a Morris team meeting. Language in Society 21: 427-445.

Kent A (2012) Responding to parental directives - What can children do when a parent tells them what to do? In: Theobold M and Danby S (eds) Disputes in Everyday Life: Social and Moral Orders of Children and Young People. New York: American Sociological Association's Studies of Children and Youth and Emerald Books, pp. 57-84.

Kuczynski L and Kochanska G (1990) Development of children's noncompliance strategies from toddlerhood to age 5. Developmental Psychology 26(3): 398-408.

Larson RW, Branscomb KR and Wiley AR (2006) Forms and functions of family mealtimes: Multidisciplinary perspectives. New Directions for Child and Adolescent Development 111: 1-15.

Lukes S (1979) Power and authority. In: Bottesmore T and Nisbet R (eds) A History of Sociological Analysis. London: Heinemann, pp. 633-677.

Paugh AL (2005) Learning about work at dinnertime: Language socialization in dual-earner American families. Discourse \& Society 16(1): 55-78.

Pearson B (1989) 'Role-ing out control' at church business meetings: Directing and disagreeing. Language Sciences 11(3): 289-304

Perakyla A (1998) Authority and accountability: The delivery of diagnosis in primary health care. Social Psychology Quarterly 61: 301-320.

Perakyla A (2002) Agency and authority: Extended responses to diagnostic statements in primary care encounters. Research on Language and Social Interaction 35(2): 219-247.

Peters RS (1967) Authority. In: Quinton A (ed.) Political Philosophy. Oxford: Oxford University Press, pp. 83-96.

Potter J and Hepburn A (2010) Putting aspiration into words: 'Laugh particles', managing descriptive trouble and modulating action. Journal of Pragmatics 42(6): 1543-1555.

Pufahl-Bax I (1986) How to assign work in an office: A comparison of spoken and written directives in American English. Journal of Pragmatics 10: 692-763.

Raymond G (2000) The voice of authority: The local accomplishment of authoritative discourse in live information broadcasts. Discourse Studies 2(3): 354-379.

Raymond G and Heritage J (2006) The epistemics of social relations: Owning grandchildren. Language in Society 35: $677-705$

Sacks H (1987) On the preferences for agreement and contiguity in sequences in conversation. In: Button G and

Lee JRE (eds) Talk and Social Organisation. Clevedon: Multilingual Matters Ltd, pp. 54-69.

Schegloff EA (1989) Reflections of language, development, and the interactional character of talk-in-interaction. In: Bornstein MH and Bruner JS (eds) Interaction in Human Development. London: Lawrence Erlbaum Associates, pp. 139-153.

Schegloff EA (1996) Confirming allusions: Toward an empirical account of action. American Journal of Sociology 102(1): 161-216.

Schegloff EA (2007) Sequence Organisation in Interaction: A Primer in Conversation Analysis. Cambridge: Cambridge University Press.

Sealey A (1999) 'Don't be cheeky': Requests, directives and being a child. Journal of Sociolinguistics 3(1): 24-40.

Searle JR (1979) Expression and Meaning: Studies in the Theory of Speech Acts. Cambridge: Cambridge University Press.

Stevanovic M (2011) Participants' deontic rights and action formation: The case of declarative requests for action. InLiSt - Interaction and Linguistic Structures 52, June 2011. Available at: http://www.inlist.unibayreuth.de/issues/52/InLiSt52.pdf.

Stevanovic M and Perakyla A (2012) Deontic authority in interaction. Research on Language and Social Interaction 45(3): 297-321.

Vine B (2009) Directives at work: Exploring the contextual complexity of workplace directives. Journal of Pragmatics 41: 1395-1405.

Walton D (1997) Appeal to Expert Opinion: Arguments from Authority. University Park: Pennsylvania State University Press.

West C (1990) 'Not just “doctors' orders"': Directive-response sequences in patients' visits to women and men physicians. Discourse \& Society 1: 85-113.

Wootton A (1997) Interaction and the Development of Mind. Cambridge: Cambridge University Press. 